\title{
Vascular Effects of Diabetes Mellitus
}

\author{
Anna-Maria Kampoli, Dimitris Tousoulis*, Kyriakoula Marinou, Gerasimos Siasos, and \\ Christodoulos Stefanadis
}

Athens University Medical School, Cardiology Department, Hippokration Hospital, Athens- Greece

\begin{abstract}
Diabetes mellitus (DM) is one of the most potent independent risk factors for the development of coronary artery disease (CAD) and is recognized as a cardiovascular disease equivalent. Compared with individuals without DM, those with $\mathrm{DM}$ have a higher prevalence of $\mathrm{CAD}$, a greater extent of coronary ischemia, and are more likely to have a myocardial infarction and silent myocardial ischemia. The vasculature of diabetic patients is more vulnerable in developing atherosclerotic plaques in comparison with the vasculature of the non diabetic individuals. Microvascular and macrovascular effects are observed in the majority of organs of diabetic patients. Endothelial dysfunction, increased stiffness of the aorta, renal artery stenosis, diabetic nephropathy, carotid artery stenosis leading to cerebrovascular insufficiency, $\mathrm{CAD}$ and heart failure are the main complications of DM on the vasculature. Therapeutic modalities such as angiotensinconverting enzyme inhibitors, angiotensin II receptor blockers, thiazolidinediones (glitazones), statins, and antioxidants may be useful in these patients.
\end{abstract}

Keywords: Atherosclerosis, glycosylation, microvascular complications, macrovascular complications.

\section{INTRODUCTION}

Coronary artery disease (CAD) accounts for about 50\% of all deaths worlwide. Diabetes mellitus (DM), and especially type $2 \mathrm{DM}$, is one of the most potent independent risk factors for the development of CAD probably related to accelerated atherosclerosis. Up to $80 \%$ of patients with type 2 DM die from cardiovascular complications and the average life expactancy is reduced by approximately 10 years. Recent studies indicate that DM is equivalent to CAD and has important effects on vasculature, including vascular endothelium, peripheral arteries, coronary arteries and the aorta [1, 2].

We discuss the effects of DM on endothelium, aorta, kidneys, brain vasculature, coronary arteries, and also we focus on the prevention and medical treatment of DM.

\section{EFFECTS OF DM ON THE VASCULATURE}

\subsection{Effects on the Endothelium}

The endothelium is an organ consisting of a single cell layer lining the intimal surface of the vasculature, which serves as a barrier between the circulation and body tissues. The endothelial cell's normal paracrine and autocrine functions, includes the synthesis of a variety of substances that mediate vascular relaxation, control local inflammation, inhibit leucocyte migration and influence platelet activation. Endothelial dysfunction encompasses multiple abnormalities, including altered vasomotor activity, vascular smooth cell (VSMC) dysfunction, overproduction of inflammatory cyto

*Address correspondence to this author at the S. Karagiorga 69, Glifada, 166 75, Athens, Greece; Tel: +30-210-7782466; Fax: +30-210-7485039;

E-mail: drtousoulis@hotmail.com kines and chemokines, impaired platelet function and abnormal coagulation. All the above perturbations lead to increased vasoconstriction, inflammation and thrombosis [3].

The endothelium of diabetic patients is more vulnerable in developing atherosclerotic plaques in comparison to the endothelium of non diabetic individuals. A variety of mechanisms may contribute to the increased risk of developing atherosclerotic plaques in patients with DM. The abnormal cluster of hyperglycemia, elevated free fatty acids, and insulin resistance which characterizes DM, acts in concert to target the endothelial cell, resulting in oxidative stress and endothelial dysfunction [4].

In DM, impaired vasodilation results from reduced nitric oxide (NO) production and increased NO inactivation [5]. Endothelial dysfunction with impaired NO release is present both in patients with type 2 DM [6] and those with insulindependent DM [7, 8]. The presence of insulin resistance alone may be associated with coronary endothelial dysfunction $[9,10]$. In addition, elevated levels of free fatty acids also contribute to reduce NO production, further impairing vascular relaxation [11, 12]. These elevated levels of free fatty acids in DM, also promote the formation of oxidized low-density lipoproteins (Ox-LDL) which consists of important initiating event for atherosclerosis. Ox-LDL can damage endothelial cells and induce the expression of adhesion molecules such as P-selectin [13] and chemotactic factors such as monocyte chemoattractant protein-1 and macrophage colony stimulating factor (CSF) $[14,15]$ and therefore contribute to endothelial dysfunction in DM.

Apart from the decreased synthesis of NO, the increased production of glycosylated end-products causes endothelial dysfunction in diabetics. Recent studies proved that endothelial function assessed by FMD (flow mediated dilatation) is 
significantly impaired in diabetic patients with inadequate glycemic control and without clinical evidence of atherosclerosis [16, 17]. Also, there is FMD dysfunction in patients of newly diagnosed type 2 DM [18]. According to a study, the accumulation of cardiovascular risk factors is associated with endothelial dysfunction in diabetic patients, and that insulin resistance as well as high blood pressure could play a pathogenic role in the development of endothelial dysfunction [19]. The administration of pioglitazone [20], atorvastatin $[21,22]$ and oral vitamin D2 [19] improve endothelial function in diabetics.

An interesting study demonstrated both reduced maximal coronary vasodilation and impairment in the regulation of coronary flow in response to submaximal increases in myocardial demand in patients with DM. These microvascular abnormalities may lead to myocardial ischemia in the absence of epicardial coronary atherosclerosis in some circumstances, and thus contribute to adverse cardiovascular events in diabetic patients [23]. Furthermore, according to studies from our group, the administration of vitamin $\mathrm{C}$ significantly increased forearm vasodilatory response to reactive hyperaemia in patients with combined DM and CAD [24, 25]. The effect of DM on endothelium is summarized in Table $\mathbf{1 .}$

Table 1. Effects of Diabetes Mellitus on Endothelium

\begin{tabular}{|c|c|}
\hline Effects & Causes \\
\hline $\begin{array}{l}\text { Diabetic endothelium is more } \\
\text { vulnerable in developing athero- } \\
\text { sclerotic plaques }\end{array}$ & $\begin{array}{l}\text { - hyperglycemia } \\
\text { - elevated free fatty acids } \\
\text { - insulin resistance } \\
\text { - oxidative stress } \\
\text { - endothelial dysfunction }\end{array}$ \\
\hline Impaired vasodilation & $\begin{array}{l}\text { - reduced nitric oxide (NO) pro- } \\
\text { duction } \\
\text { - increased NO inactivation }\end{array}$ \\
\hline $\begin{array}{l}\text { Impaired flow-mediated dilation } \\
\text { (FMD) }\end{array}$ & $\begin{array}{l}\text { - induced nitric oxide (NO) re- } \\
\text { lease } \\
\text { - increased production of glycosy- } \\
\text { lated end-products }\end{array}$ \\
\hline $\begin{array}{l}\text { Decreased response to intracoro- } \\
\text { nary infusion of adenosine }\end{array}$ & - reduced sensitivity in adenosine \\
\hline
\end{tabular}

\subsection{Effects on the Aorta}

In adults with type 2 DM, observational studies and secondary analyses of clinical trials demonstrated that poor glycemic control increased the risk of macrovascular disease. Macrovascular complications include increased stiffness of the aorta compared with the stiffness of obese and healthyweight controls, indicating premature ageing of the cardiovascular system in diabetic patients [26]. Moreover, increased aortic stiffness leads to increased systolic blood pressure and left ventricular mass and hampers coronary filling during diastole.

Large artery stiffening has been demonstrated in type 2 DM using several different methods including measurement of central pulse wave velocity, or estimation of aortic com- pliance, a technically demanding technique requiring the simultaneous measurement of stroke volume and diastolic pressure decay. According to the Hoorn Study [27], DM type 2 is associated with decreased total systemic arterial compliance, increased aortic augmentation index, and decreased carotid-femoral transit time, independently of age, sex, mean arterial pressure, heart rate, body mass index, and other potential confounders. Advanced glycation end products can form cross-links in collagen fibers, thereby decreasing the distensibility of the arterial wall. Further evidence for their role in arterial stiffness is provided by studies showing that treatment with aminoguanidine prevents or reduces the increases in arterial stiffness [28], inhibits the formation of advanced glycation end products or ALT-711 (an inhibitor of advanced glycosylation end products) [29]. The effects of DM on aorta are summarized in Table 2.

Table 2. Effects of Diabetes Mellitus on Aorta

\begin{tabular}{|l|l|}
\hline \multicolumn{1}{|c|}{ Macrovascular Effects } & \multicolumn{1}{c|}{ Results } \\
\hline \hline increased stiffness of the aorta & \begin{tabular}{l}
\multicolumn{1}{c}{ - increased systolic blood pressure } \\
- increased left ventricular mass \\
- decreased coronary filling during \\
diastole \\
- hyperglycemia causes important \\
quantitative and qualitative \\
changes in aortic wall elastin and \\
collagen \\
- advanced glycation end products \\
form cross-links in collagen fibers \\
decreasing the distensibility of the \\
aortic wall
\end{tabular} \\
\hline
\end{tabular}

\subsection{Effects on Peripheral Arteries}

\section{3.a. Effects on Kidneys}

In terms of macroangiopathy, one of the most common complications of DM is peripheral arterial occlusive disease which includes the renal arteries. The presence of noninsulin-dependent DM increases the risk of renal artery stenosis [30]. The risk of bilateral renal artery stenosis is greater in diabetic patients [31]. The prevalence of renal artery atheromatous stenosis (RAAS) in non-insulin-dependent diabetic patients ranges from 17 to $44 \%$ [32]. The prevalence increases exponentially in the presence of several risk factors such as severe arterial hypertension, severe renal insufficiency, macroangiopathy, smoking, and insulin requirement. In diabetic patients, RAAS should be investigated in patients with severe arterial hypertension, repeated pulmonary oedemas, and renal insufficiency without any clear etiology associated with a mild proteinuria and/or with a renal insufficiency secondary to the administration of angiotensin converting enzyme inhibitors or angiotensin II receptors antagonists. Asymmetrical size of the kidneys should also prompt the physician with a suspicion of RAAS. Renal arteriography is still the gold standard for diagnosing renal artery stenosis.

Microvascular effects of DM on kidneys refer mainly to diabetic nephropathy. Diabetic nephropathy occurs in both type 1 and type $2 \mathrm{DM}$, including DM due to genetic defects 
of beta-cell function. There are 3 major histologic changes in the glomeruli in diabetic nephropathy: mesangial expansion, glomerular basement membrane thickening, and glomerular sclerosis. There appear to be different pathogenetic processes leading to the pathologic mechanisms in diabetic nephropathy. Glomerulosclerosis, for example, may result from intraglomerular hypertension induced by renal vasodilatation, or from ischemic injury induced by hyaline narrowing of the vessels supplying the glomeruli [33]. The main pathogenetic mechanisms include glomerular hyperfiltration, hyperglycemia, prorenin, cytokines and nephrin expression [34]. The role of glomerular hypertension and hyperfiltration in diabetic nephropathy is reinforced by the apparent benefits of blockade of the renin-angiotensin system. Hyperglycemia may directly induce mesangial expansion and injury, perhaps in part via increased matrix production or glycosylation of matrix proteins [35]. Glycosylation of tissue proteins also may contribute to the development of diabetic nephropathy and other microvascular complications. In chronic hyperglycemia, some of the excess glucose combines with free amino acids on circulating or tissue proteins [25]. This nonenzymatic process initially forms reversible early glycosylation products and later irreversible advanced glycosylation end products [25]. Activation of cytokines, profibrotic elements, inflammation, and vascular growth factors (vascular endothelial growth factor, VEGF) may be involved in the matrix accumulation in diabetic nephropathy [36]. From the clinical point of view, the earliest clinical manifestation of renal involvement in DM is an increase in albumin excretion (microalbuminuria) [37]. Microalbuminuria is diagnosed by the existence of persistent excretion albumin values between 30 and $300 \mathrm{mg} / \mathrm{day}$ (20 to $200 \mu \mathrm{g} / \mathrm{min}$ ) [38].

\section{3.b. Effects on Brain Vasculature}

In adolescents with type 2 DM, a variety of macrovascular abnormalities have been documented. DM is associated with the presence of moderate to large atherosclerotic carotid plaques. Cerebral vascular disease resulting in cerebrovascular insufficiency is one of them. According to several studies, there is an increased incidence of stenotic atherosclerotic lesions of the internal carotid artery (ICA) in patients with DM [39]. Early diagnosis of CAD in patients with modifiable risk factors like DM may play an important role in the prevention of a consequent stroke. Patients with type $2 \mathrm{DM}$ have more echolucent plaques compared with non diabetic subjects, thus they have a higher incidence of cerebrovascular events, such as stroke [40].

Microvascular complications of DM include neuropathy. DM-associated neuropathy is a progressive disorder that affects both the autonomic and peripheral nervous systems. Ten to $18 \%$ of adult patients have evidence of nerve damage at the time that their DM is diagnosed. Similar to other microvascular complications, the risk of diabetic neuropathy in adults has been shown to increase with poor glycemic control and duration of disease [41]. Improved glycemic control improves nerve function in diabetic adult patients [42].

\section{3.c. Effects on Coronary Arteries}

The 2 major effects of DM on heart are CAD and heart failure (HF). Compared with individuals without DM, those with $\mathrm{DM}$ have a higher prevalence of $\mathrm{CAD}$, a greater extent of coronary ischemia, and are more likely to have a myocardial infarction (MI), to experience a complication associated with an MI, including postinfarction angina and $\mathrm{HF}$, and silent myocardial ischemia. According to the Framingham Heart Study, the presence of DM doubled the age-adjusted risk for cardiovascular disease in men and tripled it in women [43]. DM remained a major independent cardiovascular risk factor even when adjusting for advancing age, hypertension, smoking, hypercholesterolemia and left ventricular hypertrophy. Several studies found that the extent of the disease in the coronary arteries is greater among diabetic patients. As an example, the Thrombolysis and Angioplasty in Myocardial Infarction (TAMI) trial showed that compared with non diabetics, the diabetic patients had a significantly higher incidence of multivessel disease (66 vs 46\%) and a greater number of diseased vessels [44]. Diabetic patients also tend to have fewer coronary collateral vessels [45]. The main responsible pathophysiologic mechanisms for the increased risk of CAD are endothelial dysfunction, elevated primary and secondary platelet aggregation, coagulation abnormalities and plaque composition.

DM increases the risk of $\mathrm{HF}$ independent of CAD and hypertension and may cause cardiomyopathy. The Framingham Study firmly established the epidemiologic link between $\mathrm{DM}$ and HF. The risk of HF was increased 2.4-fold in men and fivefold in women [46]. DM predicted HF independent of coexisting hypertension or CAD. Left ventricular dysfunction due to diabetic cardiomyopathy is manifested by systolic and/or diastolic dysfunction. A variety of factors, such as autonomic neuropathy may contribute to the development of ventricular dysfunction, abnormal epicardial vessel tone and microvascular dysfunction. Among patients with HF, those with DM have higher mortality rates, as demonstrated in the Studies of Left Ventricular Dysfunction (SOLVD) [47]. Compared with non diabetics, diabetic patients were significantly more likely to be admitted for HF (risk ratio 1.6) and had higher rates at 1 year of all-cause mortality, cardiovascular mortality and mortality related to pump failure. The effects of DM on heart vessels are summarized in Table 3.

Table 3. Effects of Diabetes Mellitus on Heart Vessels

\begin{tabular}{|l|l|}
\hline \multicolumn{1}{|c|}{ Effects } & \multicolumn{1}{c|}{ Results } \\
\hline \hline Higher extent of coronary & - higher rate of myocardial infarction \\
artery disease (significantly \\
higher incidence of multives- \\
sel disease and a greater num- \\
ber of diseased vessels)
\end{tabular}

\section{PREVENTION AND MEDICAL TREATMENT}

\subsection{Prevention}

Exercise can help diabetic patients control their weight, lower blood glucose levels and decrease risk of CAD [48]. Aerobic exercise increases insulin sensitivity and, along with proper nutrition, helps restore normal glucose metabolism by decreasing body fat. Strength training also decreases body fat 
by raising the metabolism. Its main benefit, however, is increasing glucose uptake by muscles and enhancing the ability to store glucose. Reported physical activity of moderate intensity reduced the incidence of new cases of type $2 \mathrm{DM}$ in 900 non diabetic middle-aged Finnish men followed for an average of 4.2 years, whether or not they were initially at high risk for type 2 DM [49]. It is becoming increasingly clear that the epidemic of type 2 DM sweeping the globe is associated with decreasing levels of activity and an increasing prevalence of obesity the. Thus, the importance of promoting exercise as a vital component of the prevention as well as management of type 2 DM must be viewed as a high priority.

Weight reduction due to diet modifications, if sustained, can substantially improve glycemic control in patients with type 2 DM. Lifestyle intervention was effective in men and women in all age groups, and in all ethnic groups. An analysis of patients in the intensive lifestyle group found that, within the 3 components of the intervention (weight loss, diet change, and exercise), DM prevention correlated most strongly with weight loss: there was a $16 \%$ reduction in DM risk for every kilogram reduction in weight [50]. The combined effects of diet and healthy lifestyle also were important in preventing type $2 \mathrm{DM}$ in women. Almost $90 \%$ of the cases of DM in the Nurses' Health Study were found in women with obesity, lack of exercise, a poor diet, and smoking, suggesting that many cases of DM could be prevented by a healthier lifestyle [51].

As regards cigarette smoking, several large prospective trials raised the possibility that cigarette smoking increases the risk of type 2 DM. The risk appears to be graded, with increasing risk as the number of cigarettes smoked per day and pack-year history rises [52]. While a definitive causal association has not been established, a relationship between cigarette smoking and DM is biologically possible based upon a number of observations that smoking increases the blood glucose concentration after an oral glucose challenge, may impair insulin sensitivity and has been linked to increased abdominal fat distribution and greater waist-to-hip ratio [53].

\subsection{Medical Treatment}

Medical treatment includes angiotensin-converting enzyme inhibitors (ACEIs), angiotensin II receptor blockers (ARBs), thiazolidinediones (glitazones), statins, and antioxidants seem to also have an effect on cardiovascular disease (CVD) in diabetic patients.

ACEIs inhibit kininase II (angiotensin-converting enzyme), blocking the formation of angiotensin II and preventing its activation of angiotensin I receptors in the adrenal cortex, thereby decreasing aldosterone and its effects on vasculature and reducing vasoconstriction. ACEIs also inhibit the metabolism of bradykinin (BK), which causes NO/EDRF-mediated vasodilation [54].

$A R B s$ produce direct antagonism of the angiotensin II (Ang II) receptors, unlike ACE inhibitors. They displace the Ang II from the AT1 receptor, and produce their blood pressure lowering effects by antagonizing AT1-induced vasoconstriction, aldosterone release, catecholamines release, argin- ine vasopressin release, water intake and hypertrophic responses. The American Diabetes Association (ADA) recommends using ACEIs or ARBs in patients with DM and comorbid hypertension or renal disease [55]. They both improve cardiovascular outcomes and renal function in highrisk individuals with DM, as indicated in a number of major clinical trials [56-60]. According to the results of these studies, there was a decrease in mortality, nonfatal MI, stroke, in primary endpoint and in new cases of DM, after the administration of the drugs.

Thiazolidinediones are oral hypoglycemic drugs. The 2 thiazolidinediones in clinical use are rosiglitazone and pioglitazone. As antidiabetic agents, glitazones lower blood glucose by improving target cell response to insulin, without increasing pancreatic insulin secretion. In detail, thiazolidinediones increase insulin sensitivity by acting on muscle and liver to increase glucose utilization and decrease glucose production [61]. They bind to and activate one or more peroxisome proliferator-activated receptor-gamma (PPARs), which regulate gene expression in response to ligand bindind. PPAR-gamma is found predominantly in adipose tissue, pancreatic beta-cells, vascular endothelium and macrophages. Rosiglitazone and troglitazone are purely PPARgamma agonists. The results of the studies [62-64] conducted on the administration of thiazolidinediones demonstrated decrease of the overall cardiovascular risk, of MI, mortality and stroke.

It is well known that lipid abnormalities play an important part in raising the cardiovascular risk in diabetic subjects. The main components of diabetic dyslipidemia are increased plasma triglycerides, low concentration of highdensity lipoprotein cholesterol, preponderance of small, dense low-density lipoprotein, and excessive postprandial lipemia [65]. The benefits of statins in patients with type 2 DM were investigated in 2 trials: The Collaborative Atorvastatin Diabetes Study (CARDS) and The Heart Protection Study (HPS) [66]. The results of the studies showed a decrease in cardiovascular events (CAD, heart attacks, coronary revascularization, stroke or death). On the other hand, the ASPEN trial (Atorvastatin Study for Prevention of Coronary Heart Disease Endpoints in Non-Insulin-Dependent Diabetes Mellitus) [67] did not confirm the beneficial effects of statins on diabetics. In ASPEN trial 2410 patients ages 40 to 75 with type 2 diabetes (505 with prior CHD) were radomly assigned to receive atorvastatin $10 \mathrm{mg}$ daily or placebo. After a median follow-up of four years, there was no statistically significant reduction in the primary composite endpoint (cardiovascular death, nonfatal MI, coronary intervention, unstable angina, or resuscitated cardiac arrest) in all patients treated with atorvastatin. This result may relate to the overall study design, the types of subjects recruited, the nature of the primary end point, and the protocol changes required because of changing treatment guidelines. For these reasons, the results of the Atorvastatin Study for Prevention of Coronary Heart Disease Endpoints in Non-InsulinDependent Diabetes Mellitus (ASPEN) did not confirm the benefit of therapy but do not detract from the imperative that the majority of diabetic patients are at risk of coronary heart disease and deserve LDL cholesterol lowering to the currently recommended targets. 
Evidence suggests oxygen free radicals are increased in DM. These free radicals lead to a greater amount of oxidized LDL lipoproteins and other oxidized glycosylated products that facilitate the pathogenesis of atherosclerosis. The use of antioxidants such as Vitamin C, Vitamin E and beta carotene have been proposed [68]. Although small and experimental studies indicate that antioxidants might be protective, the randomized controlled trials do not support these findings; further studies are needed.

\section{CONCLUSIONS}

DM increases cardiovascular risk, and is recognized as a cardiovascular disease equivalent. Microvascular and macrovascular effects are observed in the majority of organs of diabetic patients. Increased stiffness of the aorta, renal artery stenosis, nephropathy, carotid artery stenosis leading to cerebrovascular insufficiency, coronary artery disease and heart failure are the main complications of DM on the vasculature. Medical treatment includes angiotensin-converting enzyme inhibitors, angiotensin II receptor blockers, thiazolidinediones (glitazones), statins, and antioxidants.

\section{REFERENCES}

[1] Wild S, Roglic G, Green A, et al. Global Prevalence of Diabetes: estimates for the year 2000 and projections for 2030. Diabetes Care 2004; 27: 1047-53.

[2] Amos A, McCarty D, Zimmet P. The rising global burden of diabetes and its complications: Estimates and projections to the year 2010. Diabet Med 1997; 14: S1-S85.

[3] Wheaton J, Pinkstaff S. Aspects of Diabetes Mellitus: Atherosclerotic vascular Disease and Diabetes in the Older Adult; Part I: Understanding Pathogenic Mechanisms and Identifying Risk Factors. Clin Geriatr 2006; 14: 17-25.

[4] Aljada A. Endothelium, Inflammation and Diabetes. Metab Syndr Relat Disord 2003; 1: 3-21.

[5] Hsueh WA, Quinones MJ. Role of endothelial dysfunction in insulin resistance. Am J Cardiol 2003; 92: 10J-17J.

[6] Balletshofer BM, Rittig K, Enderle MD, et al. Endothelial dysfunction is detectable in young normotensive first-degree relatives of subjects with type 2 diabetes in association with insulin resistance. Circulation 2000; 101: 1780-4.

[7] Clarkson P, Celermajer DS, Donald AE, et al. Impaired vascular reactivity in insulin- dependent diabetes mellitus is related to disease duration and low density lipoprotein cholesterol levels. J Am Coll Cardiol 1996: 28: 573-9.

[8] Makimattila S, Virkamaki A, Groop PH, et al. Chronic hyperglycemia impairs endothelial function and insulin sensitivity via different mechanisms in insulin- dependent diabetes mellitus. Circulation 1996; 94: 1276-82.

[9] Quinones MJ, Hernandez-Pampaloni M, Schelbert H, et al. Coronary vasomotor abnormalities in insulin-resistant individuals. Ann Inter Med 2004; 140: 700-8.

[10] Hsueh WA, Lyon CJ, Quinones MJ. Insulin resistance and the endothelium. Am J Med 2004; 117: 109-117.

[11] Navab M, Berliner JA, Watson AD, et al. The Ying and Yang of oxidation in the development of the fatty streak. A review based on the 1994 George Lyman Duff Memorial Lecture. Atherioscler Thromb Vasc Biol 1996; 16: 831-42.

[12] Ross R. Atherosclerosis: an inflammatory disease. N Eng J Med 1999; 340: 115-26.

[13] Vora DK, Fang ZT, Liva SM, et al. Induction of P-selectin by oxidized lipoproteins. Separate effects on synthesis and surface expression. Circ Res 1997; 80: 810-18.

[14] Cushing SD, Berliner JA, Valente AJ, et al. Minimally modified low-density lipoprotein induces monocyte chemotactic protein 1 in human endothelial cells and smooth muscle cells. Proc Natl Acad Sci USA 1990; 87: 5134-8.

[15] Rajavashisth TB, Andalibi A, Territo MC, et al. Induction of endothelial cell expression of granulocyte and macrophage colony- stimulating factors by modified low-density lipoproteins. Nature 1990; 344: 254-7.

[16] Ifrim S, Basilescu R. Early detection of atherosclerosis in type 2 diabetic patients by endothelial dysfunction and intima-media thickness. Rom J Intern Med 2004; 42: 343-54.

[17] Wu J, Lei MX, Liu L. [Changes of endothelium-dependent vasodilation in patients with impaired glucose tolerance and type 2 diabetes]. Zhong Nan Da Xue Xue Bao Yi Xue Ban 2007; 32: 609-14.

[18] Liu L, Lu ZY, Lei MX. [Effect of plasma glucose on the vascular endothelial function and analysis of relevant factors]. Zhong Nan Da Xue Xue Bao Yi Xue Ban 2006; 31: 830-3.

[19] Tsuchiya K, Nakayama C, Iwashima F, et al. Advanced endothelial dysfunction in diabetic patients with multiple risk factors; importance of insulin resistance. J Atheroscler Thromb 2007; 14: 303-9.

[20] Martens FM, Visseren FL, de Koning EJ, et al. Short-term pioglitazone treatment improves vascular function irrespective of metabolic changes in patients with type 2 diabetes. J Cardiovasc Pharmacol 2005; 46: 773-8.

[21] Konduracka E, Galicka-Latala D, Gieslik G, et al. Effect of atorvastatin on endothelial function and inflammation in long-duration type 1 diabetic patients without coronary heart disease and arterial hypertension. Diabetes Obes Metab 2008; 10(9): 719-25.

[22] Economides PA, Caselli A, Tiani E, et al. The effects of atorvastatin on endothelial function in diabetic patients and subjects at risk for type 2 diabetes. J Clin Endocrinol Metab 2004; 89: 740-7.

[23] Nahser PJ, Brown RE, Oskarsson H, et al. Maximal coronary flow reserve and metabolic coronary vasodilation in patients with diabetes mellitus. Circulation 1995; 91: 635-640.

[24] Antoniades C, Tousoulis D, Tountas C, et al. Vascular endothelium and inflammatory process, in patients with combined Type 2 diabetes mellitus and coronary atherosclerosis: the effects of vitamin C. Diabet Med 2004; 21: 552-8.

[25] Tousoulis D, Antoniades C, Tountas C, et al. Vitamin C affects thrombosis/ fibrinolysis system and reactive hyperemia in patients with type 2 diabetes and coronary artery disease. Diabetes Care 2003; 26: 2749-53.

[26] Gungor N, Thompson T, Sutton-Tyrrell K, et al. Early signs of cardiovascular disease in youth with obesity and type 2 diabetes. Diabetes Care 2005; 28: 1219-21.

[27] Schram M, Henry R, van Dijk R. Increased central artery stiffness in impaired glucose metabolism and Type 2 diabetes. Hypertension 2004; 43: 176-81.

[28] Cantini C, Kieffer P, Corman B, et al. Aminoguanidine and aortic wall mechanics, structure, and composition in aged rats. Hypertension 2001; 38: 943-48.

[29] Kass DA, Shapiro EP, Kawaguchi M, et al. Improved arterial compliance by a novel advanced glycation end-product crosslink breaker. Circulation 2001; 104: 1464-70.

[30] Valabhji S, Robinson,C, Poulter AC, et al. Prevalence of renal artery stenosis in subjects with type 2 diabetes and coexistent hypertension. Diabetes Care 2000; 23: 539-43.

[31] Courreges JP, Bacha J, Aboud E, et al. Prevalence of renal artery stenosis in type 2 diabetes. Diabetes Metab 2000; 26: 90-6.

[32] Izzedine H, Launay-Vacher V, Grimaldi A, et al. How and when to search for a renal artery atheromatous stenosis in diabetic patients? Diabetes Metab 2002; 28: 244-9.

[33] Soman S, Soman A. Diabetic Nephropathy. EMedicine, August 2006

[34] Hilgers KF, Veelken R. Type 2 Diabetic Nephropathy: Never too Early to Treat? J Am Soc Nephrol 2005; 16: 574-82.

[35] Jawa A, Kcomt J, Fonseca V. Diabetic nephropathy and retinopathy. Med Clin North Am 2004; 88: 1001-36.

[36] Hohenstein B, Hausknecht B, Boehmer K, et al. Local VEGF activity but not VEGF expression is tightly regulated during diabetic nephropathy in man. Kidney Int 2006; 69: 1654-61.

[37] Caramori M, Fioretto P, Mauer M. The need for early predictors of diabetic nephropathy risk: is albumin excretion rate sufficient? Diabetes 2000; 49: 1399-408.

[38] Tobe SW, McFarlane PA, Naimark DM. Microalbuminuria in diabetes mellitus. CMAJ 2002; 167: 499-503.

[39] Vidjak V, Hebrang A, Brkljacic B, et al. Stenotic occlusive lesions of internal carotid artery in diabetic patients. Coll Antropol 2007 31: 775-80

[40] Ostling G, Hedblad B, Berglund G, et al. Increased echolucency of carotid plaques in patients with type 2 diabetes. Stroke 2007; 38: 2074-8. 
[41] The Diabetes Control and Complications Trial Research Group. The effect of intensive diabetes therapy on the development and progression of neuropathy. Ann Intern Med 1995; 122: 561-8.

[42] Kuwabara S, Ogawara K, Harrori T, et al. The acute effects of glycemic control on axonal excitability in human diabetic nerves. Intern Med 2002; 41: 360-5

[43] Kannel W, McGee D. Diabetes and cardiovascular risk factors: The Framingham Study. Circulation 1979; 59: 8-13.

[44] Granger C, Califf R, Young S, et al. Outcome of patients with diabetes mellitus and acute myocardial infarction treated with thrombolytic agents. J Am Coll Cardiol 1993; 21: 920-5.

[45] Abaci A, Kahraman S, Eryol NK, et al. Effect of diabetes mellitus on formation of collateral vessels. Circulation 1999; 99: 2239-42.

[46] Kannel W, Hjortland M, Castelli W. Role of diabetes in congestive heart failure. The Framingham Study. Am J Cardiol 1974; 34: 2934.

[47] Shindler DM, Kostis JB, Yusuf S. for the SOLVD Investigators. Diabetes mellitus, a predictor of morbidity and mortality in the Studies of Left Ventricular Dysfunction (SOLVD) Trials and Registry. Am J Cardiol 1996; 77: 1017-20.

[48] Pan XR, Li GW, Hu YH, et al. Effects of diet and exercise in preventing NIDDM in people with impaired glucose tolerance. The Da Qing IGT and Diabetes Study. Diabetes Care 1997; 20: 537-44.

[49] Lynch J, Helmrich SP, Lakka TA, et al. Moderately intense physical activities and high levels of cardiorespiratory fitness reduce the risk of non- insulin-dependent diabetes mellitus in middle-aged men. Arch Intern Med 1996; 156: 1307-14.

[50] Hamman RF, Wing RR, Edelstein SL, et al. Effect of weight loss with lifestyle intervention on risk of diabetes. Diabetes Care 2006; 29: 2102-7.

[51] Hu FB, Manson JE, Stampfer MJ, et al. Diet, lifestyle, and the risk of type 2 diabetes mellitus in women. N Engl J Med 2001; 345: 790-7.

[52] Houston TK, Person SD, Pletcher MJ, et al. Active and passive smoking and development of glucose intolerance amnong young adults in a propective cohort: CARDIA study. BMJ 2006; 332: 1064-9.

[53] Magis D, Geronooz I, Scheen AJ. Smoking, insulin resistance and type 2 diabetes. Rev Med Liege 2002; 57: 575-81.

[54] Tousoulis D, Antoniades C, Koumallos N, et al. Novel therapies targeting vascular endothelium. Endothelium 2006; 13: 411-21.

[55] Cooke CE, Fatodu H. Physician conformity and patient adherence to ACE inhibitors and ARBs in patients with diabetes, with and without renal disease and hypertension, in a medicaid managed care organization. J Manag Care Pharm 2006; 12: 649-55.

[56] Yusuf S, Sleight P, Pogue J. Effects of an angiotensin-converting enzyme inhibitor, ramipril, on cardiovascular events in high-risk patients. The Heart Outcomes Prevention Evaluation Study Investigators. N Engl J Med 2000; 342: 145-53.
[57] Fox KM. Efficacy of perindopril in reduction of cardiovascular events among patients with stable coronary artery disease: randomised, double-blind, placebo-controlled, multicenter trial (the EUROPA study). Lancet 2003; 362: 782-88.

[58] Braunwald E, Domanski MJ, Fowler SE, et al. Angiotensinconverting-enzyme inhibition in stable coronary artery disease. $\mathrm{N}$ Engl J Med 2004; 351: 2058-68.

[59] Major outcomes in high-risk hypertensive patients randomized to angiotensin-converting-emzyme inhibitor or calcium channel blocker vs diuretic: The Antihypertensive and Lipid-Lowering Treatment to Prevent Heart Attack Trial (ALLHAT). JAMA 2002; 288: 2981-97.

[60] Nissen SE, Tuzcu EM, Libby P, et al. Effect of antihypertensive agents on cardiovascular events in patients with coronary disease and normal blood pressure: the CAMELOT study: a randomized controlled trial. JAMA 2004; 292: 2217-25.

[61] Iwamoto Y, Kosaka K, Kuzuya T, Akanuma Y, Shigeta Y, Kaneko T. Effects of troglitazone: a new hypoglycemic agent in patients with NIDDM poorly controlled by diet therapy. Diabetes Care 1996; 19: 151-6.

[62] Phillips LS, Grunberger G, Miller E, et al. Once- or twice-daily dosing with rosiglitazone improves glycemic control in patients with type 2 diabetes. Rosiglitazone Clinical Trials Study Group. Diabetes Care 2001; 24: 308-15.

[63] Home PD, Pocock SJ, Beck-Nielsen H, et al. Rosiglitazone evaluated for Cardiac Outcomes and Regulation of Glycaemia in Diabetes (RECORD): study design and protocol. Diabetologia 2005; 48: 1726-35.

[64] Dormandy JA, Charbonnel B, Eckland DJ. Secondary prevention of macrovascular events in patients with type 2 diabetes in the PROactive Study (PROspective pioglitAzone Clinical Trial In macroVascular Events): a randomised controlled trial. Lancet 2005; 366: 1279-89.

[65] Carmena R, Betteridge J. Statins and diabetes. Semin Vasc Med 2004; 4: 321-32.

[66] Colhoun HM, Betteridge DJ, Durrington PN, et al. Primary prevention of cardiovascular disease with atorvastatin in type 2 diabetes in the Collaborative Atorvastatin Diabetes Study (CARDS): multicenter randomised placebo-controlled trial. Lancet 2004; 364: 685-96.

[67] Knopp RH, d'Emden M, Smilde JG, et al. Efficacy and safety of atorvastatin in the prevention of cardiovascular end points in subjects with type 2 diabetes: the Atorvastatin Study for Prevention of Coronary Heart Disease Endpoints in non-insulin-dependent diabetes mellitus (ASPEN). Diabetes Care. 2006; 29: 1478-85.

[68] Princen HMG, van Duyvenvoorde W, Buytenhek R, et al. Supplementation with low doses of vitamin E protects LDL from lipid peroxidation in men and women. Arterioscler Thromb Vasc Biol 1995; $15: 323-6$

(c) Kampoli et al.; Licensee Bentham Open

This is an open access article licensed under the terms of the Creative Commons Attribution Non-Commercial License (http://creativecommons.org/licenses/by-nc/3.0/) which permits unrestricted, non-commercial use, distribution and reproduction in any medium, provided the work is properly cited. 